\title{
Gender medicine as a tool for implementing the right to health
}

\author{
Francesca Rescigno \\ Department of Political and Social Sciences, University of Bologna, Bologna, Italy \\ E-mail: francesca.rescigno@unibo.it
}

Received 12 September 2021

Accepted 29 December 2021

\begin{abstract}
.
BACKGROUND: The COVID-19 pandemic has increased the interest in the right to health, which represents a relatively new concept brought about by progress in medical science and the evolution of societies. The Italian Constitution, in article 32, states the right to health without specifications about the parameter of sex, assuming that this fundamental right is property of women and men indiscriminately.

OBJECTIVE: To assess whether the right to health has actually been achieved in an equal way from the standpoint of sex, and whether a hypothetically "neutral" approach is actually convincing and profitable in this context.

METHODS: This paper analyzes the topic of gender medicine from a scientific and legal perspective, based on current medical literature and its implementation in the Italian and European legal systems.

RESULTS: Gender medicine is the only credible response to sex- and gender-based inequalities affecting the right to health, as it provides tools to address persisting inequalities in prevention and treatment, thus pursuing health for all: women and men. CONCLUSIONS: The importance of this path was underlined also by the Summit and the Rome Declaration of 21 May 2021, acknowledging that the topic of sex and gender can no longer be overlooked in focusing a correct and equal healthcare approach.
\end{abstract}

Keywords: COVID-19, Rome declaration, gender medicine, gender, healthcare

\section{The health equality paradigm}

The World Health Summit held in Rome in May 2021 took on an even greater significance in view of the historical moment that the planet has been experiencing for over a year and a half now ${ }^{1}$. Today, more than ever, the right to health is no longer just as an object of study for experts. It became a common feeling among citizens; since the COVID-19 pandemic has increased the general interest in the right to health and in everything that revolves around it.

The affirmation of the right to health represents a relatively recent phenomenon [1]. In the past it would have never been possible for citizens to think about the idea of claiming rights in the health sector, both

\footnotetext{
${ }^{1}$ At the end of the summit, the "Rome Declaration" was approved (Rome, 21 May 2021). It states, "inter alia": "We reaffirm that the pandemic continues to be an unprecedented global health and socio-economic crisis, with disproportionate direct and indirect effects on the most vulnerable, on women, girls and children, as well as on frontline workers and the elderly. It will not be over until all countries are able to bring the disease under control and therefore, large-scale, global, safe, effective and equitable vaccination in combination with appropriate other public health measures remains our top priority, alongside a return to strong, sustainable, balanced and inclusive growth". The Rome Declaration was confirmed at the G20 meeting in Rome in early September.
} 
because a universal health system provided to all citizens by a single public body did not exist, and because medicine had not achieved the progress we see today.

The evolution of the studies and knowledge of the various types of diseases, their causes, symptoms, and possible remedies, has transformed medicine into a science allowing patients to claim a real right to be able to enjoy "good health". Therefore the right to health, as we know it today, is the result of a slow evolution that has led to its current position among economic, social, and cultural rights enshrined in national and international Charters. This proves that its realization is progressive and conditioned by a series of variables that range from the use of economic resources to the progress of medical science, as well as from the creation of infrastructures, up to the involvement and empowerment of the people who can benefit from this right.

The World Health Organization (WHO) identifies health as a state of physical and mental well-being and considers it not only as an individual but also a collective factor. In the context of health, not only physical homeostasis but also psychological and social components are involved, so that the subject, woman or man, is considered in its three dimensions: biological, mental and social. Consequently, health does not mean only absence of any illness.

The Preamble of the Constitutive Act of the WHO contains the enunciation of some principles considered "fundamental for happiness, for harmonious relations and for the safety of all peoples". The enjoyment of the highest possible level of health is defined as "one of the fundamental rights of every human being", and the concept of health is linked to those of peace and security, which are also global goals under the system of the United Nations.

The main goal of the World Health Organization, briefly outlined in article 1, is the achievement of the highest possible level of health by all peoples, identified precisely with " a state of complete physical, mental and social well-being and not merely the absence of disease or infirmity".

The definition of health contained in the Preamble is based on two elements, one individual and the other collective: from the individual point of view, health is a state of complete physical, mental and social well-being, not merely the absence of disease and infirmity, and the enjoyment of the highest attainable standard of health constitutes a fundamental right of every human being.

On the other hand, from the collective perspective it is clear that the health of all peoples represents a fundamental condition for the realization of peace and security and relies on the best collaboration both among individuals and between States. This is why the unequal progress in the various countries in improving health and fighting diseases translates into a common danger.

Considering health as a state of complete well-being has unfortunately led to an excess of medicalization aimed at achieving global physical, mental, psychological, emotional and social well-being, even though this is actually an almost impossible goal to achieve. The great changes that have taken place worldwide since 1948, the incredible increase in life expectancy and the consequent aging of the population, have in fact inevitably led to an increase in chronic diseases. As a consequence, today lives are longer and longer, as well as strongly medicalized making the complete physical well-being a goal difficult to reach and lead to a new definition of health. Therefore, in 2011 WHO defined health as "the ability to adapt and manage oneself in the face of social challenges, physical and emotional", focusing on the ability of the person to live with the disease in its various stages and to be able to self-determine with respect to the treatment and patient dignity. It is evident the shift that occurred from the static formulation elaborated in 1948 towards the affirmation of a more dynamic one in the present days which is based on resilience, or better, on the ability to face, maintain and restore one's own integrity, balance, and sense of well-being. With the 2011 definition the person can no longer be considered as a simple passive receptor of healthcare, 
actually becoming an actor with a propulsive role in achieving and maintaining the best possible state of psycho-physical health.

Health is therefore a complex value that concerns the management of one's own body, mind and all the choices related to them. In this sense health becomes one of the methods of personal empowerment. From this point of view, it is easy to understand how health is also a parameter of equality. In fact, since the Constituent Assembly was established, the inseparable link between health and the full realization of freedom and equality of individuals has been highlighted. The fundamental right to health is stated in Italian Constitution in article 32 and our Country was the first to approve a constitution that "in giving constitutional importance to the interests connected with the health of citizens, gave them a complete discipline [2]".

Health is a right but also a value that contributes to defining the person by operating according to the principle of equality ${ }^{2}$. Article 32 gives everyone the right to health without making any reference to the parameter of sex, assuming that this fundamental right is indiscriminately property of women and men. However, it remains to be seen whether the realization of the right to health has actually taken place in a neutral way from the point of view of sex, and above all whether a hypothetical neutral approach is actually convincing and profitable in this context.

\section{The gender medicine revolution}

Point 14 of the Rome Declaration refers to the need for meaningful involvement with civil society and women's organizations, focusing on the importance of social determinants and the gender dimension with respect to the right to health ${ }^{3}$. Health is in fact affected by multiple variables that can lead to health inequalities. These variables are known as the "determinants of health", meaning factors that influence the health status of an individual and - more extensively - of a community. These factors include individual behaviors, as well as political, socio-economic, and even cultural contexts. The determinants of health are manifold and can change over the course of a person's life. They include personal behaviors and lifestyles; social factors that can turn out to be an advantage or a disadvantage for the person; the living and working conditions; access to health services; general socio-economic, cultural and environmental conditions and, of course, genetic factors.

The advent of the COVID-19 pandemic, that has affected our lives in the last years, showed, if this was not already clear enough, how fundamental health is in the global context. Thus, empowering each person

\footnotetext{
${ }^{2}$ The Court of Cassation already stated in 1979: "Health, as well as being the object of care and intervention by the general community, is protected primarily, unconditionally and absolutely as a way of being of the human person ... the transparent reference to art. 2 of the Constitution makes clear both the content and the type of protection that is proper to the subjective right, indeed to the absolute right". See Cass. Civ. section un., 6 October 1979, n. 5172, in Civil Justice, 1980, 1, 357.

${ }^{3}$ Point 14 of the Rome Declaration of 21 May 2021: "Increase the effectiveness of preparedness and response measures by supporting and promoting meaningful and inclusive dialogue with local communities, civil society, frontline workers, vulnerable groups, women's and other organisations and all other relevant stakeholders and by countering misinformation and disinformation. Underpin this with trust and transparency in relation to governance and decision-making, arising from the timely and culturally adapted communication of accurate information, of evidence and of uncertainty, and of lessons learned from the COVID-19 pandemic response and previous public health emergencies. Undertake health promotion and work on the social determinants of health to address other critical health issues such as non-communicable diseases, mental health and food and nutrition, as part of efforts to enhance overall resilience to future health crises and in addition ensure an age-and gendersensitive response to future crises".
} 
to exercise control over their own health and its determinants strengthens communities and improves life. In this sense, equal opportunities for access to education, work, housing and a decent income are all conditions that cross-cuttingly promote the achievement and maintenance of a good health and a good health contributes to the increase of productivity, a more efficient workforce, a healthier ageing, reduced health and social costs and a reduction in tax losses. Therefore, health policies must be conducted jointly with social and economic policies, involving both the population and all levels of government.

Some health determinants appear quite obvious, such as poverty or poor housing conditions, others act indirectly, such as unemployment, or a low level of education. Although it is true that life expectancies have significantly increased in the last century, despite this undoubted improvement, there are still many variables that create great inequalities and put the health and survival of thousands of people at risk. The examination of individual determinants that affect health brings to the topic of women who involuntarily present an evident health gap as far as it regards their economic, social, and cultural subordination. This is a common trait that characterizes the female gender in almost every country in the world ${ }^{4}$.

As a matter of fact, even if women and men have different life expectancies (consisting of an average of few more years for women), this original "advantage" does not imply a position of privilege but is the consequence of individual determinants that have very little to do with health policies, since in reality sex is still a source of discrimination today. Women continue to be discriminated in all economic, social, political and cultural spheres. The chronic female subordination inevitably affects the health factor. Among the determinants that influence the realization of the right to health, coefficients such as poverty, precarious and poorly paid employment, stereotyped education limited only to certain sectors, as well as the obstacles that the person encounters in his/her realization are all extremely relevant in relation to the level of health condition. Unfortunately, these elements are all very present in women's lives. When it comes to the choice of the future studies, women are mainly oriented towards humanities, for which they are considered more suitable with their sensitivity and according to the "vocation" of mother. Moreover, they encounter considerable difficulties when it comes to the access and the career in labor market. For women it is difficult to reach top positions and salaries comparable to those of men. There are also many difficulties in reconciling family needs (always inexplicably remitted almost exclusively to women) and working ones. This is also known as the so-called "double presence" that women are called to fulfill being at the same time engaged in the role of "angels of the hearth" and tireless workers. The consequence is not only the loss of competitiveness in the field of work, but also problems of psycho-physical stress that weigh heavily on health conditions of women [3].

In short, women, because of their position of economic-social and working subordination, are subject to multiple determinants that negatively affect their health status. Their discrimination in terms of work, economics and family severely afflicts their enjoyment of the fundamental and universal right to health.

\footnotetext{
${ }^{4}$ It seems appropriate at least to mention the difference between sex and gender. Traditionally, individuals are divided into men and women on the basis of their biological differences and in the common feeling sex and gender constitute a whole. In reality they represent two different aspects of identity considering that sex constitutes a genetic data, a set of biological, physical and anatomical characters that usually produce a male/female binarism. Gender represents a cultural construction, the representation, definition and incentive of behaviors that cover the biological set and give life to the status of man/woman. Generally, biological sex means the ascription of an individual to two binary categories, M (male) or F (female); from the genetic point of view this distinction is based on the difference of the twenty-third pair of chromosomes (the other 22 are the same for both), the one defined as the sex chromosomes, which in females is XX, while in males XY. Gender identity, on the other hand, is generally defined as the specific dimension of individual identity linked to the subjective perception of one's masculinity/femininity, that is, the gender to which a person feels he/she belongs to, a definition that, albeit its conciseness, highlights how gender identity has to do with a subjective perception of the self.
} 
The position of objective subordination of women must therefore be taken into particular consideration when developing health policies. If the promotion of health is a fundamental goal for everyone, it cannot take place in the same way for women and men. This is due to the fact that the two sexes have different health determinants and women start from a situation of objective inequality and disadvantage that must necessarily be taken into account.

In this sense, undifferentiated policies, based on the false assumption that men and women from the same geographical area and in the same period of time have the same health needs, only results in exacerbating the inequalities and the distance that already exists between the two sexes, in an essential sector both for the individuals and the whole community.

Being a woman is therefore a negative individual determinant with respect to the enjoyment of the right to health. In addition, sex can be added to other remarkable factors, thereby causing multiple discriminations. Belonging to the female sex is not the only discriminating aspect with respect to women's health, which must also relate to the pseudo-asexual consideration that medical science has developed in the implementation of the right to health. For a long time, the woman's body has been the subject of a personalized investigation from a medical point of view only in the context of issues related to sexuality and in particular with respect to reproductive capacity. The interest of science has been almost monopolized by this aspect of female physiology, while for the other declinations of the right to health a "neutral" approach has been carried out. This of course hid a substantially androcentric vision of health and medicine. Medical science needed in any case a model to refer to, a prototype to conduct investigations and to study the human body, pathologies and possible treatments. Therefore, despite the more than evident diversity existing between women's bodies and men's bodies, it was preferred to basically ignore this difference by using only the male sex as a standard for investigation, without worrying if, in this way, the health of women could be compromised.

Medical science and pharmacology have acted without taking into account the principle of equality, whose application in the context of the right to health should have led to an equal treatment of those aspects that are similar, as well as a different treatment for those situations that are different. Therefore, women and men should have been taken into consideration with their differences, being them biologically different in many aspects and not only when it comes to the reproductive system. Male sex should not have been used as the only model of reference model.

Health management has long been (and largely continues to be) developed on the basis of an alleged equality declined in the sense of a hypothetical "male-neutral" standard. The issue is particularly relevant, not only because the physical differences that characterize men and women have been essentially ignored, but also because at the same time social determinants have also been ignored. In particular, factors mostly related to the highlighted position of subordination that characterizes women in society have not been taken into consideration so far.

Medicine has therefore demonstrated a substantially "macho" vocation, by electing as the only model of reference that of the "neutral man", an imaginary human being, male, of Caucasian race, with a height of at least one meter and seventy $\mathrm{cm}$ and an average weight of seventy kilos. This model has become, and unfortunately very often continues to be, the unit of measurement for medical and pharmaceutical science. Therefore, the differences in the occurrence and development of the various pathologies, (symptoms, clinical course, response to drugs, experience and psychological reaction, in men and women), have long been ignored. This is particularly true for differences regarding sex characteristics (biological aspects), as well as gender aspects (psychological, social, historical and cultural elements related to sex). 
It was 1991 when the cardiologist Bernadine Patricia Healy, professor and head of cardiology at the Johns Hopkins Hospital, wrote for the New England Journal of Medicine the famous editorial, entitled "The Yentl Syndrome".

On this occasion she commented about some specific medical studies, which showed that in cases of ischemic heart disease, before an alert event or a myocardial infarction, fewer women had been subjected to a coronary examination, notwithstanding the presence of symptoms with the same entity and intensity as those experienced by men [4]. This reduced attention used to remain substantially unchanged even after the occurrence of a sentinel event and despite hospitalization.

Dr. Healy recurred to a significant reference for the title of her article, referring to a story by Isaac Singer (Yentl The Yeshiva Boy). She compared the position of the female patient to that of Yentl, the protagonist of the story. Yentl had to shave his hair and dress up like a man, in order to be able to study the Talmud. In the same way, the cardiologist highlighted how female patients had to simulate a "male" symptomatology to be properly treated. Otherwise they would have experienced great difficulties to be believed by doctors when manifestations of cardiovascular problems occurred.

The article had a huge echo, but it was not enough to change a well-established trend, even if it had the merit of raising a problem that did not only concern cardiology but every sector of medicine and persist even today.

Health cannot be considered as an asexual concept at all. Sex and gender make the difference, both in pharmaceutical and clinical research; therefore, in order to integrate the principle of equality and the right to health in a virtuous manner, it is necessary to abandon stereotypes that address the differences between men and women only to the reproductive system.

This is how the revolution of gender medicine was born. This term refers the complex interaction and integration between sex (intended as the biological and functional differences between the organisms) and the psychological-cultural behaviors of the individuals deriving from their ethnic, educational, social, and religious background.

Gender medicine should not be considered as women's medicine. Studying gender medicine does not mean limiting the scientific and clinical attention to the pathologies that most frequently affect women, or to pathologies related to the reproductive system, or in general to the health of women only. It means investigating and understanding how the diseases of all organs and systems occur in the two sexes, evaluating not only the differences related to the biological factor of sex, but also those related to gender differences with respect to the symptoms of diseases, the need for different diagnostic pathways and interpretations of the results. It also requires the evaluation of the differences in response to drugs and the need to use different drugs, as well as differentiated approaches to the prevention of diseases.

Gender medicine is therefore everyone's medicine. Even if inevitably the most investigated subject turn out to be women, this is due to the fact that for millennia the model of reference in medicine has been almost exclusively the man. This is why, if on the one hand a lot has been discovered in relation to men's health, on the other hand, an entire universe is still to be discovered when it comes to women's health.

Gender medicine aims to understand the mechanisms through which sex-gender differences affect the health status, the insurgence and the course of many diseases, as well as the outcomes of therapies. Despite being subject to the same diseases, men and women present very different symptoms, progression in the diseases and response to treatments. Hence the need to focus on the study of gender-specific differences in diseases, inserting this new dimension of medicine in all medical areas. Gender medicine proposes a different and innovative approach that aims to ensure the most appropriate treatment designed on the basis of sexual characteristics, age, but also of the socio-economic and cultural status of the individual. All these factors are taken into account in order to avoid as much as possible diagnostic-therapeutic inequalities not 
motivated by clear scientific evidence. The WHO itself has remarked the importance of the attention required by sex and gender as fundamental factors in determining health or disease. Already in 1998 the WHO had acknowledged the differences between the two sexes and included gender medicine in the Equity Act as evidence that the principle of equity had to be applied to the access and appropriateness of healthcare, considering the individual in his/her specificity and as belonging to a genus with defined characteristics.

Gender medicine represents a real transversal innovation in the field of health. It is, based on the assumption that even in the field of health and medicine we can talk about sex and gender inequalities. Pervasive discriminations occur in all societies and are structured in such a way to damage more the health of girls and women. Yet, men can equally be affected by inequalities when it comes to health issues.

It is well known that a system of prevention, diagnosis and treatment that does not take into account sex and gender differences compromises equity, appropriateness of healthcare, respect and implementation of the right to health. This is precisely the area in which gender medicine operates.

Italy immediately appeared very attentive to the implementation of this new healthcare approach and approved the Law n. 3 of 2018 on "Delegation to the Government for clinical trials of medicines as well as provisions for the reorganization of the health professions and for the health management of the Ministry of Health". This law provides for a gender-oriented medicine in all of its applications at national level, both in the clinical trials of drugs (art. 1, paragraph 1) and throughout the clinical-diagnostic process (art. 3). The law concretizes, for the first time in a regulatory text, years of studies on gender medicine, stating that the recognition of sexual and gender differences in research, diagnosis, prevention and treatment represents an unavoidable evolution to guarantee equity and appropriateness in the healthcare sector, thereby safeguarding the right to health enshrined in the article 32 of the Constitution.

On the basis of the abovementioned law, the Plan for the application and dissemination of gender medicine was approved. This also provides for the creation, at the Istituto Superiore di Sanità, of a special Observatory dedicated to Gender Medicine in order to provide the Minister of Health with data that require to be presented annually to the Chambers. The observatory/supervisory body was definitively established in February 2021.

The importance of this path, which is hoped to be continued with even more strength and determination, was underlined also by the Summit and the Rome Declaration occurred last May. On this occasion it was recognized how the enhancement of sex and gender in the healthcare approach can no longer be overlooked, since "the silent revolution of gender medicine has overcome the first major obstacle in its path, that of being accepted as an undeniable and necessary paradigm shift. This is just the beginning. Now is the time to embark on a true interdisciplinary journey and invest resources, both academically and clinically, so that gender medicine becomes an integral part of how we teach and apply modern medicine for the benefit of men and women alike [5]".

\section{Conflict of interest}

None to report.

\section{References}

[1] Ferrara R, Il diritto alla salute: i principi costituzionali. In: Ferrara R, Sartoretti C (eds). Trattato di Biodiritto. Salute e sanità. Milano: Giuffrè; 2010. p. 4, where the author underlines how: "the right to health, which today appears to us as a rule of constitutional civilization (...) almost obvious and obvious (...), represents the fruit of a long and tiring process". 
[2] Mortati C, La tutela della salute nella Costituzione italiana. Rivista infortuni. 1961, and Mortati C. Problemi di diritto pubblico nell'attuale esperienza costituzionale repubblicana, Milano: Giuffrè; 1971, p. 435.

[3] On this point, Balbo L. La doppia presenza. Inchiesta, 1978, p. 32.

[4] Healy B. The Yentl syndrome. New England Journal of Medicine. 1991;274, In the text, the author documents the systematic discrimination experienced by patients suffering from heart diseases, such as acute ischemia both in the diagnostic and in the therapeutic phase. It highlighted the occurrence of fewer hospitalizations and prescribed diagnostic investigations, fewer interventions such as by-pass and angioplasty compared to men, lack of women in clinical trials for drug testing and diagnostic technologies. As a result, a higher mortality rate for women with heart disease was proven. Unfortunately, despite the resonance of this article, heart diseases in women continue to be little considered, insofar as heart attacks stand out among the main causes of female death, surpassing in percentages those of men.

[5] Glezerman M. Foreword: Gender-Specific Medicine - Environment and Biology Principles of Gender-Specific Medicine. In: Legato MJ (ed) Amsterdam: Elsevier; 2017. 